\title{
Efficiency of Grease Residue from Grease Trap Waste Water Treatment for Candles Production
}

\author{
Nisa Pakvilai
}

\begin{abstract}
This study aims to investigate the properties of grease residue from grease trap waste water treatment and to determination the performance of candles from grease residues. Grease residue from grease trap wastewater treatment system at Canteen in Valaya Alongkorn Rajabhat University Under the Royal Patronage. Grease processing at the source such as houses and restaurants is unsuitable for common types of pollutants, which are relatively small. The average amount of grease residue from the grease trap was 200 grams / day. The average household was 2.6 kilograms per day. The results showed that the physical properties of stored grease for more than 2 weeks were gray, high viscosity and foul odor. For new grease, is yellow light, soft texture, and odorless. This study uses a new fat density of $1.002 \mathrm{~g} / \mathrm{mL}$, the moisture content $58.04 \%$, and the heating value was $8148.63 \mathrm{kcal} / \mathrm{kg}$. The physical properties of the candles are produced at an appropriate ratio of 3: 1 (paraffin: grease residue). In comparison with conventional candles, the candles last for 2 hours and 10 minutes, but the candles are 3: 1 for 2 hours and 8 minutes, and 15 minutes with smoke.
\end{abstract}

Index Terms-Grease residue, waste water treatment, candles production.

\section{INTRODUCTION}

The environmental problems have risen along with economic growth population growth and urbanization. Thailand's $20^{\text {th }}$ National Economic and Social Development Plan (from 2017 to 2021) reminds that, "At present the country's natural resources and environmental quality are deteriorating, and have become a weakness in maintaining the basis of production, services and sustainable living". Therefore, we have set out developing directions and strategies to achieving the objectives of "Security, Prosperity, and Sustainability" [1]. Water is an important resource for human life after use in various activities, it is drained into the natural water source. Currently, the total waste water treatment system in Thailand is 100 wastewater treatment plants with a capacity of about 3.2 Million $\mathrm{m}^{3} /$ day [2]. The characteristics of wastewater are different pollutants, can be separate into 3 categories are physical, chemical and biological characteristic [3].

The major water pollution problem in the Valaya Alongkorn Rajabhat University's natural waters is the fat oil and grease in the wastewater. Oil and grease are the important parameters that are used in water quality measurement.

Manuscript received May 25, 2018; revised November 14, 2018.

Nisa Pakvilai is with Environmental Science Program, Faculty of Science and Technology, Valaya Alongkorn Rajabhat University under the Royal Patronage, Patumthanee, Thailand (e-mail: nisa@vru.ac.th).
Grease is lightweight and tendency to floats on the water surface under quiescent conditions. In the community wastewater with $10 \%$ of total organic matter [4]. Grease is found mostly in foods like meat fats, lard, cooking oil, shortening, and dairy products [5]. Most of the contaminated oil and grease are from cooking activities in kitchen and canteen that are released into the environment.

Contamination of greases into surface water causes unattractive and intermittent conditions. The permeability of oxygen from the air to the water source results in water pollution problems [6]. Reducing the amount of oil and grease at the source, and promoting the use of technology in oil and grease management, will reduce problems and impacts on water resources such as the use of grease traps waste water treatment. Oil and grease has the natural tendency to float on the water surface under still conditions. The use of grease traps waste water treatment are produced as grease is required to dispose of it properly.

A candle is a source of light with one or more combustible wicks that are surrounded by a burning mass which is solid or semisolid at room temperature $\left(20{ }^{\circ} \mathrm{C}\right.$ to $\left.27{ }^{\circ} \mathrm{C}\right)$ [7]. In Thailand's community product standards are quality requirements that are appropriate to the community product are acceptable, and ensure consumer confidence in product selection, with a focus on sustainable development. Candles product. This Community Product Standard covers candles made from natural and synthetic materials. The product code is $987 / 2005$. [8]

Grease residue are used to describe semisolid lubricants and applies to a material consisting of a soap, petroleum and candle [9], [10]. This study was an experimental study on the grease content of grease trap waste water treatment from canteen of Valaya Alongkorn Rajabhat University under the Royal Patronage, for Candles Production. Grease residue from the grease trap for 3 months, accumulated $200-500 \mathrm{~kg}$ (wet weight). This is a potential that can be produced candles.

\section{MATERIAL AND METHOD}

\section{A. Materials and Equipment}

Raw material in this study is fat oil and grease residue was collected from the grease trap waste water treatment tank in canteen from Valaya Alongkorn Rajabhat University. The equipment for analyze were used include: Separatory funnel (2L), evaporation disc, water bath, filter paper $(110 \mathrm{~mm}$.) No.40, funnel, beaker (100, $600 \mathrm{~mL})$, automatic bomb calorimeter, furnace, hot air oven, desiccators, and crucible. Chemical agent: sodium sulfate anhydrous, n-Hexane.

\section{B. Method}


Raw material in this study is grease residue was collected from the grease trap waste water treatment tank in canteen from Valaya Alongkorn Rajabhat University. The grease residue that is stored is divided into two periods: the grease residue in the system for more than one month is called "the old grease residue" and the grease residue that lasts two weeks, called "the new grease residue". This study were analyzes physical characteristic: color is used by observation test, Odor to threshold ratio test, and density. The chemical characteristic analyzes: moisture content, ash content, volatile content, fixed carbon, and heating value. The study of the fuel properties of grease residue will be carried out in a wet and dry condition. The study of the properties of candles is based on the standard of community products in Thailand. The study consists of 3 components characteristic for standardize: general, color, and odor [8].

\section{RESULTS}

Water quality at ponds receiving effluent discharged from the canteen showed that Fat oil and grease (FOG) analysis was in the range of 499 to $777 \mathrm{mg} / \mathrm{L}$. Biological Oxygen Demand (BOD) range between 481 to $2348 \mathrm{mg} / \mathrm{L}$. Suspended solid (SS) range between 352 to $480 \mathrm{mg} / \mathrm{L}$.

Mean concentration of water quality analysis showed that the mean of fat oil and grease was $615 \pm 144.4 \mathrm{mg} / \mathrm{L}$, with the standard value not exceeding $100 \mathrm{mg} / \mathrm{L}$. The average biological oxygen demand of 1,511 $4948.2 \mathrm{mg} / \mathrm{L}$, which the standard requires that no more than $200 \mathrm{mg} / \mathrm{L}$. Finally, the average of suspended solid at $421 \pm 64.7 \mathrm{mg} / \mathrm{L}$, which the standard value not exceed $0.5 \mathrm{mg} / \mathrm{L}$. The results showed that all samples are exceeds the surface water standard in Thailand.

TABLE I: PHYSICAL-CHEMICAL CHARACTERISTIC OF WASTEWATER FROM POND IN VALAYA ALONGKORN RAJABHAT UNIVERSITY

\begin{tabular}{|c|c|c|}
\hline Parameter & Time & \\
\hline \multirow{4}{*}{$\begin{array}{l}\text { Fat oil and grease (FOG) } \\
\mathrm{mg} / \mathrm{L}\end{array}$} & 1 & 499 \\
\hline & 2 & 777 \\
\hline & 3 & 570 \\
\hline & mean $\pm \mathrm{SD}$ & $615 \pm 144.4$ \\
\hline \multirow{4}{*}{$\begin{array}{l}\text { Biological Oxygen } \\
\text { Demand (BOD) } \\
\mathrm{mg} / \mathrm{L}\end{array}$} & 1 & 2,348 \\
\hline & 2 & 1,703 \\
\hline & 3 & 481 \\
\hline & mean \pm SD & $1,511 \pm 948.2$ \\
\hline \multirow{4}{*}{$\begin{array}{l}\text { Suspended Solid (SS) } \\
\text { mg/L }\end{array}$} & 1 & 432 \\
\hline & 2 & 480 \\
\hline & 3 & 352 \\
\hline & mean \pm SD & $421 \pm 64.7$ \\
\hline
\end{tabular}

The results of characteristic of grease residues from the grease trap waste water treatment tank in canteen from Valaya Alongkorn Rajabhat University shown in Fig. 1: (a) The invention to grease trap waste water treatment tank before discharge into the pond. (b) Grease from grease trap at canteen and (c) Grease residue separated waste. The grease residues used in this study are divided into 2 types: 1 ) the old grease residue is dark gray color, texture is muddy and sticky, and strong odor 2) the new grease residue is yellow light, soft texture, and odorless.

The results of grease residues chemical characteristic analysis are shown in Table I. The test was divided into wet and dry grease residues. The percentage of moisture content was $77.291 \pm 0.006$ and $1.703 \pm 0.183$, respectively.

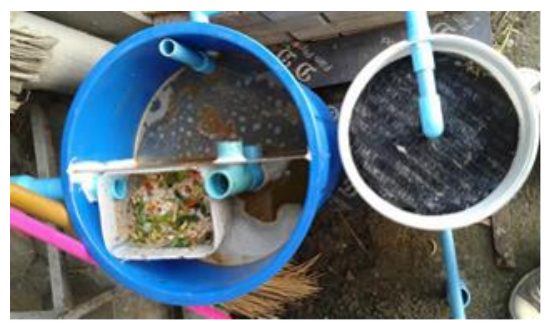

(a)

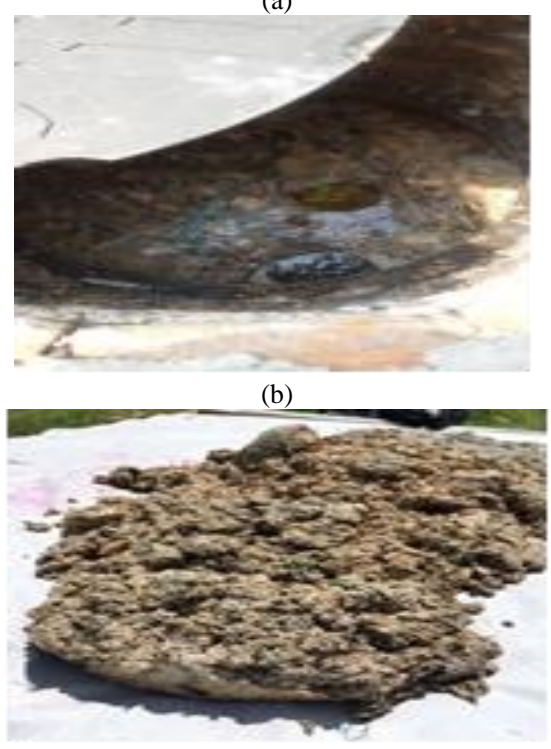

(c)

Fig. 1. Preparation of grease residue from canteen (a) Grease trap wastewater treatment system [11]; (b) Grease from grease trap at canteen; (c) Grease residue separated waste

TABLE II: PHYSICAL-CHEMICAL CHARACTERISTIC OF GREASE RESIDUE

\begin{tabular}{cccc}
\hline \hline Type & Time & $\begin{array}{c}\text { Moisture content } \\
(\mathbf{\%})\end{array}$ & $\begin{array}{c}\text { Ash content } \\
(\mathbf{\%})\end{array}$ \\
\hline \multirow{3}{*}{ Wet } & 1 & 77.990 & 1.8277 \\
& 2 & 76.870 & 1.696 \\
& 3 & 77.014 & 1.678 \\
& mean \pm SD & $77.291 \pm 0.006$ & $1.734 \pm 0.008$ \\
\multirow{2}{*}{ Dry } & 1 & 1.613 & 0.142 \\
& 2 & 1.914 & 0.121 \\
& 3 & 1.582 & 0.100 \\
\hline \hline
\end{tabular}

In physical-chemical characteristic of grease residue was showed in Table II. In wet samples, the average percentage of moisture content was $77.291 \pm 0.006$ and average of ash content was $1.734 \pm 0.008$, respectively. In dry samples, the average percentage of moisture content was $1.703 \pm 0.183$ and average of ash content was $0.121 \pm 0.021$, respectively.

In Table III was showed the chemical characteristic of grease residue. The mean percentage of volatile content were $20.582 \pm 0.702$ in wet samples and $94.135 \pm 0.147$ in dry samples, respectively. The average fixed carbon content were $1.181 \pm 0.157$ (wet sample) and $4.041 \pm 0.332$ (dry sample), respectively, and the average heating value was $8,149 \pm$ $29,569 \mathrm{kcal} / \mathrm{kg}$ (wet sample), and 8,242 \pm 42.721 (dry sample), $\mathrm{kcal} / \mathrm{kg}$, respectively.

In the step of preparation the candles component to 
processing are mixed of grease residue, paraffin and B wax was shown in Fig. 2. First, in figure (a) remove the grease from the grease trap wastewater treatment system and separate the large amount of waste, and then remove the contaminants from the grease sample using by filter cloth. In Fig. 2(b) boiled of grease residue with water, until the water is clear. Lastly, in Fig. 2(c) boiled of grease residue with paraffin and B wax in difference ratio. The mixture of grease, paraffin, and B. wax were mixed together in different proportions boil and stir. Lightly heat while stirring continuously without causing air bubbles.

TABLE III: THE CHEMICAL CHARACTERISTICS OF GREASE RESIDUES

\begin{tabular}{lcccc}
\hline \hline Type & Time & $\begin{array}{c}\text { Volatile } \\
\text { content } \\
(\boldsymbol{\%})\end{array}$ & $\begin{array}{c}\text { Fixed carbon } \\
\mathbf{( \% )}\end{array}$ & $\begin{array}{c}\text { Heating value } \\
(\mathbf{C a l} / \mathbf{g})\end{array}$ \\
\hline \multirow{3}{*}{ Wet } & 1 & 19.811 & 0.372 & 8,181 \\
& 2 & 21.185 & 0.249 & 8,123 \\
& 3 & 20.749 & 0.560 & 8,142 \\
& mean \pm SD & $20.582 \pm 0.702$ & $1.181 \pm 0.157$ & $8,149 \pm 29.569$ \\
& 1 & & & \\
\multirow{2}{*}{ Dry } & 2 & 94.294 & 4.137 & 8,233 \\
& 3 & 94.003 & 3.672 & 8,289 \\
& mean \pm SD & $94.135 \pm 0.147$ & $4.041 \pm 0.332$ & $242 \pm 42.721$ \\
\hline \hline
\end{tabular}

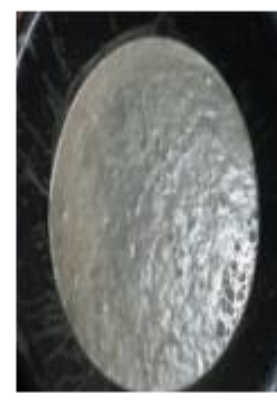

(a)

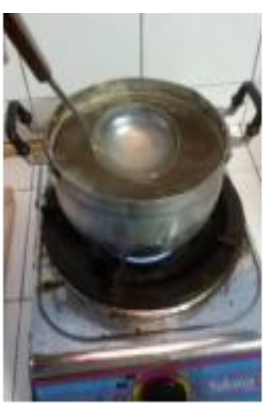

(b)

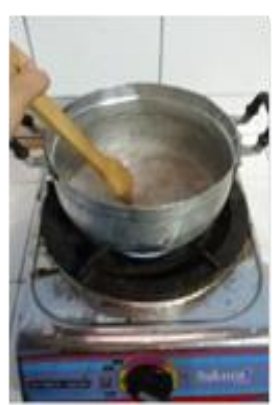

(c)
Fig. 2. Preparation of candles using by grease residue: paraffin: B wax (a) Filtered the grease residues (b) Boiled grease residue and water (c) Boiled grease residue: paraffin: $\mathrm{B}$ wax.

TABLE IV: GREASE RESIDUE AND PARAFFIN RATIO TO MOLDING OF CANDLES

\begin{tabular}{ccc}
\hline Type & CANDLES & \\
\hline \hline & $\begin{array}{c}\text { Molding } \\
\text { (old grease } \\
\text { residue) }\end{array}$ & $\begin{array}{c}\text { Molding } \\
\text { (new grease } \\
\text { residue) }\end{array}$ \\
\hline Grease residue: paraffin (3:1) & Can't be formed & Can't be formed \\
Grease residue: paraffin (2:1) & Can form, but not & Can form, but \\
Grease residue: paraffin (1:1) & Can form, but not & not complete \\
& Can form, but \\
Grease residue: paraffin (1:2) & Can form & not complete \\
Grease residue: paraffin (1:3) & Can form & Can form \\
\hline \hline
\end{tabular}

The candle molding is used as a stainless steel material. After boiling, the fat is homogeneously mixed and poured into the mold and filled with candles was shown in Fig. 3. Candles made from grease residue are $20 \mathrm{~cm}$, and diameter at $1 \mathrm{~cm}$. In preparing candles for molding, it is necessary to do so while the candles are still hot so that they can be formed. In candle molding, bubbles cannot be produced on candles to achieve candle production standards. In Thailand community product standards, general characteristic of candles must have the right shape, no fracture, no air bubbles, candles are the size and length suitable for work. From Fig. 3, it is found that the candles produced are generally standardized.

Possibility to molding of grease residue and paraffin ratio. In Table IV, shows the results of candles made from old and new grease residue. Grease residue content mixed with paraffin in the ratio of $1: 3$, both old and new grease residue is well formed, as it contains less grease residue than paraffin and has the highest number of candles. The grease residue with paraffin wax in ratio 1: 2 (both of old and new grease residue) can be formed as grease residue is less than that of paraffin, but the number of candles forming is less than that of grease residue to paraffin ratio of 1: 3 . Grease residue mixed with paraffin in the ratio of $2: 1,1: 1$ can be formed but incomplete because of the fat content of paraffin and paraffin wax, resulting in incomplete candle molding.

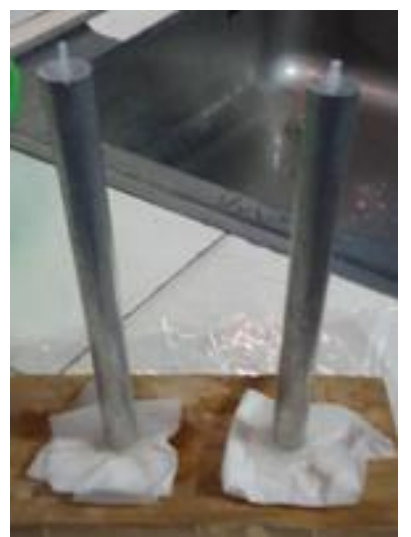

(a)

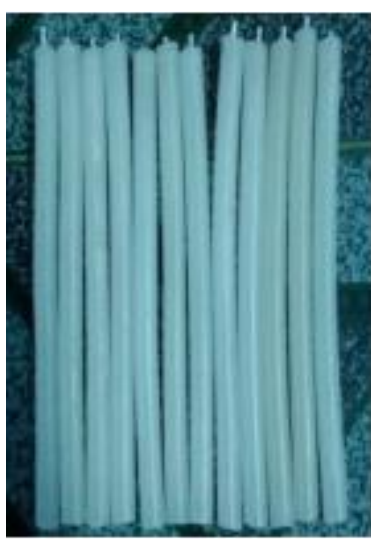

(b)
Fig. 3. Candle moulding and filling the candlewick (a) Candle moulding (b) Candles from grease residue.

TABLE V: EFFICIENT COMBUSTION TIME OF CANDLES

\begin{tabular}{llc}
\hline \multicolumn{1}{c}{ Type } & Ratio & Duration of use \\
\hline Wholesale candle & & 2 hours $10 \mathrm{~min}$ \\
Grease residue (new): paraffin & $1: 2$ & 1 hour $55 \mathrm{~min}$ \\
Grease residue (new): paraffin & $1: 3$ & 2 hours $2 \mathrm{~min}$ \\
Grease residue (old): paraffin & $1: 2$ & 1 hour $50 \mathrm{~min}$ \\
Grease residue (old): paraffin & $1: 3$ & 2 hours $5 \mathrm{~min}$ \\
\hline \hline
\end{tabular}

The results in Table $\mathrm{V}$, comparative analysis of candle burn duration between grease to paraffin and conventional candles revealed that the candles had the longest burning time of 2 hours 10 minutes. The ignition time is 2 hours 5 minutes burning of grease residue with paraffin wax in ratio of 1: 3 by weight (old grease). Grease residue with paraffin wax in ratio of 1: 3 By weight (new greasy residue), the ignition time is 2 hours 2 minutes because the fat is less than the paraffin mixture, resulting in a long burning time. The grease residue content of the paraffin wax was 1: 2 by weight (new greasy residue), the flame retardant was 1 hour 55 minutes. The grease residue content to paraffin ratio was 1:2 by weight (old greasy residue), it is 1 hour 50 minutes because it contains less paraffin wax than paraffin wax in 1:3 ratio.

TABLE VI: SMOKE TIME FROM COMBUSTION PROCESS OF CANDLES

\begin{tabular}{lcc} 
Type & Ratio & Duration of use \\
Wholesale candle & & $10 \mathrm{~min}$ \\
Grease residue (new): paraffin & $1: 2$ & $25 \mathrm{~min}$ \\
Grease residue (new): paraffin & $1: 3$ & $40 \mathrm{~min}$ \\
Grease residue (old): paraffin & $1: 2$ & $20 \mathrm{~min}$ \\
Grease residue (old): paraffin & $1: 3$ & $30 \mathrm{~min}$ \\
\hline
\end{tabular}


The results of the comparative analysis of the smoke generation period of the candles are shown in Table VI. It was found that the candles had the smallest smoke duration of 10 minutes because the burning of paraffin caused less smoke. The smoke that is going to be black smoke will be periodically without candle thaw. The smoke of grease residue (new): paraffin wax (1:2) was 25 minutes, and ratio $1: 3$ was 40 minutes. The smoke of grease residue (old): paraffin wax (1: 2) was 20 minutes, and ratio 1:3 was 30 minutes.

Economic value of candles made from grease residue. The results of the economics study showed that: the fixed cost is 70 baht. Variable cost is 390 baht when it is formed into a candle. The best ratio is 1: 3 when compared to 300 baht $(8$ hours, candles sold in the market are 9 books and 32 baht can produce a profit of 352 baht.

\section{CONCLUSION}

The results showed that the physical properties of stored grease for more than 2 weeks were gray, high viscosity and foul odor. For new grease, is yellow light, soft texture, and odorless. This study uses a new fat density of $1.002 \mathrm{~g} / \mathrm{mL}$, the moisture content $58.04 \%$, and the heating value was $8,148.63$ $\mathrm{kcal} / \mathrm{kg}$. The physical properties of the candles are produced at an appropriate ratio of 3: 1 (paraffin: grease residue). In comparison with conventional candles, the candles last for 2 hours and 10 minutes, but the candles are 3: 1 for 2 hours and 8 minutes, and 15 minutes with smoke. The recommendation in this study are as follows: In the fat to boil, the fat should be refilled and should not use old fat because it has a strong smell. To boil, light fire should be fired to boil the grease residue with paraffin and $\mathrm{B}$. Wax because it will cause eruption. To pour the candle into the mold should be poured slowly to prevent bubbles, because it will cause a candle hole.

\section{ACKNOWLEDGMENT}

I am grateful to Miss Thanyakorn Ruangthip for their assistance in sample collection and work in laboratory for physical and chemical analysis.

\section{REFERENCES}

[1] The Twelfth National Economic and Social Development Plan (2017 2021). Bangkok: Office of the National Economic and Social
Development Board (NESDB); Office of the Prime Minister. [Online]. Available:

http://www.nesdb.go.th/nesdb_en/ewt_w3c/ewt_dl_link.php?filename =develop_issue $\&$ nid $=4345$

[2] Pollution Control Department. (2016). Thailand's Pollution Situation Report 2015. [Online]. Available: http://infofile.pcd.go.th/mgt/report51NEB_4mgt.pdf

[3] N. Pakvilai, "Efficiency of biochar from agricultural waste to remove heavy metals in water," International Proceedings of Chemical, Biological and Environmental Engineering, 2015, vol. 89, pp. 23-28.

[4] Pollution Control Department. (2003). Guide to management of sludge from wastewater treatment system. Project to set criteria and guidelines for management of sludge from wastewater treatment system. [Online]. Available: http://infofile.pcd.go.th/water/manual_Station09.pdf

[5] B. Alam, "Control and management of greasy waste in Melbourne: performance review and optimization option," Master of Engineering Science, The University of Melbourne, Australia, 2003.

[6] B. Kaigate, S. Ungsoongnern, J. Kaewdam, and P. Bunprom, "The efficiency of grease trap made from recycled material as a wastewater treatment for homes and public vendors at Soi Soda community, Dusit District, Bangkok," Journal of Environment Management, 2011, vol. 7, pp. 30-42.

[7] Quality Association for candles. (2016). Candle: Quality Assurance RAL-GZ041. [Online]. Available: https://www.guetezeichen-kerzen.com/RAL-GZ041_guetezeichen-ker zen_en.pdf

[8] Office of Industrial Product Standards. Ministry of Industrial Community Product Standard of Candle. [Online]. Available: http://tcps.tisi.go.th/pub/tcps987_48.pdf

[9] UK Essays. (2018). Determination of oil and grease in water. Biology Essay. [Online]. Available: https://www.ukessays.com/essays/biology/determination-of-oil-and-gr ease-in-water-biology-essay.php

[10] M. Jiramaitree, "The development of grease tank using coconut husk as a filter," Master thesis, Bangkok: Graduate School, Srinakharinwirot University, 2008.

[11] M. Jankhaw, P. Polmasree, and J. Hinsui, "The study of grease trap efficiency in wastewater treatment from a la carte restaurant," presented at the 6th Academic Science and Technology Conference 2018,2018

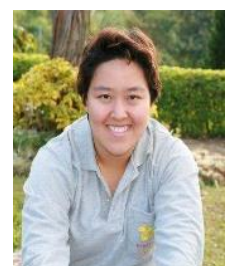

Nisa Pakvilai was born in Bangkok, Thailand, on 27 March 1979. He got the bachelor degree in environmental science program from Rajabhat Suan Dusit Institute, Thailand; the master degree's in environmental technology Program from King Mongkut's University of technology Thonburi (KMUTT), Thailand; the doctoral degree in environmental science program from Chaiang Ma University, Thailand.

He worked as a lecturer in environmental science program, Faculty of Science and Technology, Valaya Alongkorn Rajabhat University under the Royal Patronage. His work is starting from 2003 to nowadays. He had appointment to assistant professor in September 2016.

His research fields are solid waste management and alternative renewable energy. 